\title{
Türkiye'nin En Çok Endüstrileşmiş Bölgesinde Pandemi Döneminde Oküler Travma Sebebi ile Acile Başvuran Hastaların Özellikleri*
}

\author{
Berna AKOVA, Sertaç Argun KIVANÇ \\ Bursa Uludağ Üniversitesi Tıp Fakültesi, Göz Hastalıkları Anabilim Dalı, Bursa.
}

\begin{abstract}
ÖZET
Amacımız, pandemi döneminde karantina uygulanan Mart, Nisan ve Mayıs aylarında acil servise başvuran oküler travma hastalarının özelliklerini değerlendirmek ve karantinanın oküler travmalara etkisini araştırmaktır. Mart, Nisan ve Mayıs 2020 tarihlerinde toplam 821 hasta, 2019 yılının aynı aylarında 1356 hasta çalışmaya dahil edildi. Çalışma yaş gruplarına göre <19 yaş, 19-64 yaş ve $>64$ yaş olmak üzere 3 gruba ayrıldı. Yıllara ve karantina olup olmadığına göre 20192 alt gruba ve 20203 alt gruba ayrıldı. 2019 yılında hastaların ortalama yaşı $35,3 \pm 15,3$ yll iken 2020 yllında 36,7 $\pm 14,6$ yll idi. $(\mathrm{p}=0,039)$ Kapalı glob yaralanma insidans1 2019 ' da \% 79,2 iken 2020' de \% 83,6 idi. $(\mathrm{p}<0,05)$ Yanık insidansı 2019' da \% 10,4 iken 2020' de \% 6,6 idi. Adneksiyal yaralanma ve kapalı glob yaralanma oranları 19 yaşından küçük yaş grubunda 2020' de önemli ölçüde daha düşük bulundu. (sırasıyla $<0.05,<0.05$ ). Farklı karantina stilleri günlük oküler travma sebebi ile başvuran hasta sayılarını etkilemedi. Pandemi döneminde oküler travma mekanizmaları, yaralanma bölgeleri ve demografik özellikleri önemli ölçüde değişmiş bulundu. Pandemide kapalı glob yaralanma insidansı artmış, yanık azalmıştır. Ancak açık glob yaralanmaları ve adneksiyal yaralanmalar değişmemiştir.
\end{abstract}

Anahtar Kelimeler: COVID 19. Glob yaralanması. Kimyasal yanık. Oküler travma. Pandemi.

The Characteristics of Patients Applied to Emergency due to Ocular Trauma during Pandemic

\begin{abstract}
Our aim was to evaluate the characteristics of ocular trauma patients who applied to emergency and to investigate the effect of quarantine on ocular trauma in the period of the pandemic in March, April, and May when the quarantine was implemented. In March, April and May 202082 patients, in same months of 20191356 patients were included in the study. According to age groups, the study was divided into 3 groups such as <19 years old, between 19 and 64 years old, and >64 years old. According to years and whether there is a quarantine, 2019 was divided into 2 subgroups and 2020 into 3 subgroups. The mean age of patients in 2019 were found as $35.3 \pm 15.3$ years and in 2020 $36.7 \pm 14.6$ years. $(\mathrm{p}=0.039)$ The incidence of the closed globe injuries was $79.2 \%$ in 2019 whereas $83.6 \%$ in $2020 .(<0.05)$ The incidence of the burns was $10.4 \%$ in 2019 whereas $6.6 \%$ in 2020. Adnexal injury and closed globe injur rates were found significantly lower in 2020 than 2019 in the age group $<19$ years. $(<0.05,<0.05$ respectively). Different quarantine styles did not affect daily patient numbers .In the time of pandemic, ocular trauma mechanisms, injury sites and demographics were significantly changed. The incidence of closed globe injuries increased and burn decreased in pandemic. However open globe injuries and adnexal injuries did not change.
\end{abstract}

Key Words: Chemical burns. COVID 19. Globe injury. Ocular trauma. Pandemic.

Gelis Tarihi: 17.Ocak.2021

Kabul Tarihi: 09.Mart.2021

Bu çalışmanın ön bulguları Türk Oftalmoloji Derneği Ulusal Kongresi'nde (12.12.2020, çevrimiçi) sözlü bildiri olarak sunulmuştur.

Dr. Sertaç Argun KIVANÇ

Bursa Uludağ Üniversitesi Tıp Fakültesi,

Göz Hastalıkları Anabilim Dalı,

Bursa.

Tel:0505 9235004

E-posta: sakivanc@gmail.com

Yazarların ORCID ID Bilgisi:

Berna AKOVA: 0000-0003-0995-5260

Sertaç Argun KIVANÇ: 0000-0002-0932-6977
Koronavirüs salgını 2019'un sonunda başlayıp, 2020 boyunca devam etti ${ }^{1}$. Pandemi hastanelerine kabuller bu dönemde birçok farklı parametreden etkilendi ${ }^{2,3}$. Türkiye'nin ilk resmi vakası 2020 Mart ayında tespit edildi; ve bu tarihten Aralık 2020 tarihine kadar 2 milyondan fazla vakaya COVID-19 teşhisi kondu ${ }^{4}$. Türkiye'de Mart, Nisan ve Mayıs 2020'de, farklı yaş gruplarına farklı günlerde olmak üzere klasik karantinadan farklı bir şekilde karantina uygulandı ${ }^{5}$. Türkiye'de pandeminin ilk aylarında, 19 yaşından küçüklere ve 64 yaş üstü kişilere karantina uygulandı. 19 ile 64 yaş arasındaki grup için hafta sonları karantina uygulandi.

Oküler travmalar, göz hastalıkları acil durumlarının çoğunluğunu oluşturur ve körlüğün önemli nedenle- 


\section{B. Akova ve S.A. Kıvanç}

rinden biridir ${ }^{6,7}$.Ancak pandemi dönemde göz travmalarının demografisinde değişiklikler olduğu farklı çalışmalarda gösterilmiştir. Pediatrik ve geriatrik oküler travma ile ilgili daha önceki çalışmalarda verilen demografik özellikler pandemi dönemde evde kalma stratejisi nedeniyle değişmek durumunda kalmıştır. $\mathrm{Bu}$ değişim, bazı ülkelerde artış, bazılarında ise düşüş olarak ortaya çıkmıştır ${ }^{8-12}$. Bu çalışmada amacımız, COVID-19 pandemi döneminde oküler travmaya bağlı olarak Marmara Bölgesi'ndeki üçüncü basamak referans merkeze yapılan başvuruların demografik özelliklerini değerlendirmek; ve pandemi yılını önceki yılla karşılaştırmaktı ve farklı karantina stillerinin oküler travma hastalarına etkisini araştırmaktı.

\section{Gereç ve Yöntem}

Pandemi döneminde Bursa Uludağ Üniversitesi Tıp Fakültesi acil servisine Mart, Nisan ve Mayıs aylarında göz travması ile başvuran toplam 838 hastanın dosyası retrospektif olarak incelendi ve 821 hasta çalışmaya dahil edildi. Çalışma grubunu karşılaştırmak için bir önceki yılın (2019) periyodik özellikleri göz ardı etmemek amacıyla da aynı dönemde (Mart, Nisan, Mayıs) acile oküler travma ile başvuran 1385 hastanın dosyaları geriye dönük olarak incelendi ve 1356 hasta çalışmaya dahil edildi. Çalışma Helsinki Bildirgesi'ne uygun olarak yapıldı. Çalışma için, Uludağ Üniversitesi Tıp Fakültesi Klinik Araştırmalar Etik Kurulu'ndan onay alındı (Karar No: 2021-4/33).

Hastaların demografik özellikleri, göz travmaları ve göz travma tipleri ile karantina uygulanıp uygulanmamasının pandemi dönemi acil oküler travma başvurularına etkileri, önceki dönemle karşılaştırmalı olarak incelendi.

\section{Çalışma grupları}

Çalışma yaş gruplarına göre karantina durumuna göre $<19$ yaş, 19-64 yaş arası ve > 64 yaş olmak üzere 3 gruba ayrıldı. $<19$ yaşında ve $>64$ yaşında olanlar çalışma süresinin çoğunda tamamen karantina altında idi. 19 ile 64 yaşları arasında olan kişiler ise hafta içi serbest, hafta sonları ise çoğunlukla karantina altına alınmıştı.

Yıllara ve karantina olup olmadığına göre 2019 yılı 2 alt gruba ve 2020 yılı 3 alt gruba ayrıldı. Pandemiden önceki yıl (2019), Mart, Nisan ve Mayıs hafta içi ve hafta sonu olarak 2 gruba ayrildı. Pandemi y1lında (2020), Mart hafta içi günleri $<19$ yaş ve $>64$ yaş karantinaya alındığı için Mart hafta içi günleri yarı karantina grubu olarak belirlendi. Mart hafta sonlar1, yarı karantina hafta sonu grubu olarak belirlendi. Nisan ve Mayıs 2020'de, hafta içi günler yarı karantina hafta içi olarak kabul edilirken, tüm yaş grupları için hafta sonları ve resmi olarak karantina günleri tam karantina olarak kabul edildi. Mayıs ayının son hafta sonu karantina tüm gruplara uygulanmadığı için Mart ayındaki hafta sonları gibi yarı karantina hafta sonu olarak değerlendirildi.

Gruplar aşağıda verilmiştir:

2019 Hafta içi grubu: Mart, Nisan, Mayıs 2019'da hafta içi başvuran hastalar

2019 Hafta Sonu grubu: Mart, Nisan, May1s 2019'da hafta içi başvuran hastalar

2020 Yarı Karantina Hafta İçi Grubu: Mart, Nisan, Mayıs 2020 hafta içi başvuran hastalar (tam karantinanın ilan edildiği günler hariç)

2020 Yarı Karantina Hafta Sonları Grubu: Mart 2020'nin tüm hafta sonları ve Mayıs ayının son hafta sonu başvuran hastalar

2020 Tam Karantina Grubu: Nisan, Mayıs 2020'de tam karantina ilan edildiği günlerde başvuran hastalar

\section{İstatistiksel Analiz}

Araştırmada istatistiksel verilerin analizinde SPSS 23 veri analiz programı (IBM) kullanılmıştır. Çalışma verilerinin dağılımının normal olup olmadığı OneSample Kolmogorov Smirnov testi ile belirlendi. Demografik veriler için tanımlayıcı istatistiksel yöntemler kullanıldı. Yaş grupları, başvuru şikayetleri ve uygulama sürelerini karşılaştırmak için Pearson KiKare testi kullanıldı. Karantina dönemlerine göre kabul edilen ortalama hasta sayısının istatistiksel karşılaştırması için t testi kullanıldı. Sütun yüzdesini karşılaştırmak için $\mathrm{Z}$ testi kullanıldı. İstatistiksel anlamlılık düzeyi tüm istatistiksel testlerde $\mathrm{p}<0,05$ olarak belirlendi.

\section{Bulgular}

2019 yılı Mart, Nisan ve Mayıs aylarında toplam 1356 hasta göz travması nedeniyle acil servise başvurdu. Pandemi yılında (2020) toplam hasta sayıs1 821 idi. Demografik veriler Tablo I'de verildi. 2019 yılında hastaların ortalama yaşı $35,3 \pm 15,3$ yıl iken 2020 y1lında $36,7 \pm 14,6$ y1l olarak bulundu. Yaş ortalamaları arasındaki fark istatistiksel olarak anlamlı bulundu $(\mathrm{p}=0,039)$. Ondokuz yaş altı başvuru sahiplerinin yaş ortalamas1 2019'da 9,1 $\pm 5,1$ y1l iken 2020 'de $6,9 \pm 5,2$ yıldı. Aradaki fark istatistiksel olarak anlamlıydı $(\mathrm{p}=$ 0,005). Altmışdört yaş üstü başvuru sahiplerinin yaş ortalamas1 2019'da 73,9 $\pm 7,3,2020$ 'de 70,6 \pm 3,8 idi. Aradaki fark istatistiksel olarak anlamlıydı $(\mathrm{p}=0,032)$. Oküler travmaların nedenleri Tablo II'de verildi. 2019 çalışma döneminde ev kazası insidansı \%7,3 iken 2020 çalışma döneminde \%5,1 olmuştur. Aradaki fark istatistiksel olarak anlamlıyd. Yaralanma tipleri Tablo III'te verildi. Kapalı glob yaralanmalarının insidansı 2019'da \%79,2 iken 2020'de \%83,6 idi. Aradaki fark istatistiksel olarak anlamlı bulundu $(<0,05)$. Yanık insidans1 2019'da \%10,4 iken 2020 'de \%6,6 idi. Aradaki fark istatistiksel olarak anlamlı bulundu $(<0,05)$. Açık glob yaralanmaları (AGY'ler) ve adneksiyal 


\section{COVID 19 Pandemisi Döneminde Oküler Travmalar}

Yaralanmalar (AY) insidansları istatistiksel olarak anlamlı bulunmadı. Yaş gruplarına göre her iki yılda acil servislere yapılan başvurular Tablo IV'te verildi. Kapalı glob yaralanmalarının (KGY) 2019-2020 yaş gruplarına göre dağılımı anlamlı olarak farklı bulundu $(\mathrm{p}=0,001)$. Ayrıca 19 yaş altı, yaş grubunda AY oranı 2020'de 2019'a göre önemli ölçüde düşük bulundu. $(<0.05)$ Ayrıca KGY'ları 2020 yılında aynı yaş grubunda 2019'dan daha düşük bulundu (<0.05). 2019 yılında $851(\% 62,8)$ yabancı cisim (YC) ile başvuran hasta varken bunların 119'unda (\%14) YC bulunamamıştır. 2020 yılında yabancı cisim ile başvuran 584 $(\% 71,1)$ hasta varken bunların 113'ünde (\%19) YC bulunamamıştır. Yabancı cisim insidansı farklılıkları istatistiksel olarak anlamlı bulundu $(<0.001)$. Yabanc1 cisimlerin oküler yapılara göre dağılımı benzer bulun$\mathrm{du}(\mathrm{P}=0.242)$. Yabanc1 cisim yerleri Tablo V'te verildi. Korneal YC görülme sıklığı 2020 yılında daha az bulundu. 2019 yılında 5 göz içi YC (\%0.7) izlenirken 2020 y1lında 1 göz içi YC $(\% 0,2)$ izlendi. Acil serviste ilk muayene raporlarına göre 2019 yılında 896 (\%66) hastada ve 2020 y1lında 594 (\%72) hastada kornea yaralanması meydana geldi; 2019' da 127 (\%9) hastada ve 2020'de 99 hastada (\%12) konjunktival yaralanma; 2019'da $5(\% 0,4)$ ve 2020'de $10(\% 1,2)$ hastada skleral yaralanma; 2019'da 20 (\%1,5) hastada ve 2020'de 9 (\%1) hastada hifema; 2019'da 2 hastada (\%0.15) ve 2020'de $1(\% 0,1)$ hastada kristalin lens travması mevcuttu. Her iki yılda da travmatik retina dekolmanı görülmedi, Toplam periorbital travmalar ve adneksiyal yaralanmalar 2019'da $124 \quad(\% 9,1)$ ve 2020'de 70 (\%8,5) idi. Aradaki farklar istatistiksel olarak anlamlı değildi. ( $\mathrm{p}=0,62)$ Tüm adneksiyal yaralanmalar Tablo VI'da verildi. Orbita medial duvar yaralanmaları 2019 'da tüm orbital yaralanmaların \%33'ü iken 2020'deki tüm orbital yaralanmaların \%14'ünü oluşturuyordu. 2019'da Mart, Nisan ve Mayıs aylarında maksillofasiyal yaralanma olmamıştı, Ancak 2020'de maksillofasiyal yaralanma oranı \%9 idi Karantina gruplarına göre günlük ortalama hasta sayıs1 Tablo VII'de verilmiştir. 2019 ile 2020 arasında KGY, AY ve yanıklarda önemli düşüş oldu. 2020 yılında farklı karantina grupları için ortalama hasta sayısında istatistiksel bir fark yoktu. (Tablo VII).

Tablo I. Oküler travma nedeniyle 2019 ve 2020 y1lında başvuran hastaların demografik verileri

\begin{tabular}{|c|c|c|c|c|}
\hline & & 2019 & 2020 & $\mathrm{P}$ değer \\
\hline \multicolumn{2}{|l|}{ Sayı } & 1356 & 821 & \\
\hline \multirow[t]{4}{*}{ Yaş } & & $35,3 \pm 15,3$ & $36,7 \pm 14,6$ & $0.039 *$ \\
\hline & $<19$ & $9,1 \pm 5,1$ & $6,9 \pm 5,2$ & $0.005^{*}$ \\
\hline & $19-64$ & $38,1 \pm 10,8$ & $37,8 \pm 10,8$ & $0.574^{*}$ \\
\hline & $64>$ & $73,9 \pm 7,3$ & $70,6 \pm 3,8$ & $0.032^{*}$ \\
\hline \multicolumn{2}{|l|}{ Kadın cinsiyet oranı } & $\% 11,2$ & $\% 10,1$ & $0.423^{\text {** }}$ \\
\hline \multirow[t]{3}{*}{ Taraf } & OD & $\% 48$ & $\% 48$ & $<0.05^{\star \star \star}$ \\
\hline & OS & $\% 46$ & $\% 47$ & $<0.05^{\star \star \star}$ \\
\hline & OU & $\% 6$ & $\% 5$ & $<0.05^{\star \star \star}$ \\
\hline Haftasonu başvuru & & $\% 35,2$ & $\% 27,6$ & $<0.001^{* *}$ \\
\hline
\end{tabular}

OD:Sağ göz, OS: Sol göz, OU: Bilateral göz *T test, **KiKare, ${ }^{* * * Z}$ test
Tablo II. 2019 ve 2020 Mart, Nisan, Mayıs aylarında yaralanma sebepleri

\begin{tabular}{|lrrrrr|}
\hline \multicolumn{1}{|c}{ Yaralanma Sebebi } & 2019 & & 2020 & & P değeri $^{\star}$ \\
\hline & & & & & \\
\hline Fırlayan yabancı cisim & 873 & 64.4 & 571 & 69.5 & $<0.05$ \\
İş ilişkili kaza & 103 & 7.6 & 45 & 5.5 & $>0.05$ \\
Evv kazası & 99 & 7.3 & 42 & 5.1 & $<0.05$ \\
İnsan ilişkili kaza & 42 & 3.1 & 21 & 2.6 & $>0.05$ \\
İnsan saldırısı & 42 & 3.1 & 23 & 2.8 & $>0.05$ \\
Hayvan saldırısı & 5 & 0.4 & 5 & 0.6 & $>0.05$ \\
Bitki yaralanması & 31 & 2.3 & 31 & 3.8 & $<0.05$ \\
Düşme/ Yüksekten düşme & 17 & 1.3 & 16 & 1.9 & $>0.05$ \\
Motorlu araç kazası & 13 & 1.0 & 15 & 1.8 & $>0.05$ \\
Okul kazası & 7 & 0.5 & 0 & 0 & $<0.05$ \\
Bilinmeyen yaralanmalar & 124 & 9.2 & 52 & 6.4 & $<0.05$ \\
Total & 1356 & 100 & 821 & 100 & \\
\hline
\end{tabular}

Tablo III. 2019 ve 2020 Mart, Nisan, Mayıs aylarında yaralanma tiplerinin karşılaştırılması

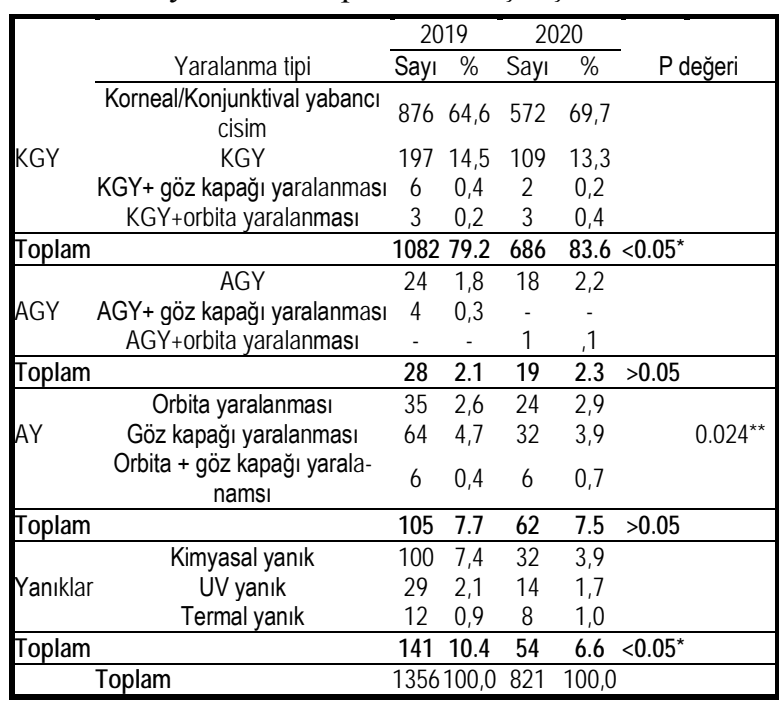

KGY: Kapalı glob yaralanması, AGY: Açık glob yaralanması, AY: Adneksal yaralanma,

*Z test, **Ki Kare testi

Tablo IV. Yaş gruplarının yaralanma tiplerine göre dağılımı ve 2019 ile 2020 Mart, Nisan, Mayıs aylarının karşılaştırılması

\begin{tabular}{|c|c|c|c|c|c|c|c|}
\hline \multirow{5}{*}{ KGY } & \multirow[b]{2}{*}{$\begin{array}{c}\text { Yaş } \\
\text { Grupları }\end{array}$} & \multicolumn{2}{|c|}{2019} & \multicolumn{2}{|r|}{2020} & \multirow[b]{2}{*}{$\begin{array}{c}Z \text { test } \\
P \\
\text { değeri }\end{array}$} & \multirow[b]{2}{*}{$\begin{array}{l}\text { Ki-Kare } \\
\text { P değeri }\end{array}$} \\
\hline & & Sayı & $\begin{array}{c}\text { Oran } \\
(\%)\end{array}$ & Sayı & Oran (\%) & & \\
\hline & $<19$ age & 102 & $9,4 \%$ & 33 & $4,8 \%$ & $<0.05$ & 0.001 \\
\hline & 19-64 age & 958 & $88,5 \%$ & 631 & $92,0 \%$ & $<0.05$ & \\
\hline & $>64$ age & 22 & $2,0 \%$ & 22 & $3,2 \%$ & $>0.05$ & \\
\hline \multirow[t]{3}{*}{ AGY } & $<19$ age & 7 & $25,0 \%$ & 4 & $21,1 \%$ & $>0.05$ & 0.374 \\
\hline & $19-64$ age & 16 & $57,1 \%$ & 14 & $73,7 \%$ & $>0.05$ & \\
\hline & $>64$ age & 5 & $17,9 \%$ & 1 & $5,3 \%$ & N/A & \\
\hline \multirow[t]{3}{*}{ AY } & $<19$ age & 47 & $44,8 \%$ & 18 & $29,0 \%$ & $<0.05$ & 0.095 \\
\hline & $19-64$ age & 54 & $51,4 \%$ & 39 & $62,9 \%$ & $>0.05$ & \\
\hline & $>64$ age & 4 & $3,8 \%$ & 5 & $8,1 \%$ & $>0.05$ & \\
\hline \multirow[t]{3}{*}{ Yanıklar } & $<19$ age & 17 & $12,1 \%$ & 7 & $13,0 \%$ & $>0.05$ & 0,960 \\
\hline & $19-64$ age & 122 & $86,5 \%$ & 46 & $85,2 \%$ & $>0.05$ & \\
\hline & $>64$ age & 2 & $1,4 \%$ & 1 & $1,9 \%$ & $>0.05$ & \\
\hline \multirow[t]{3}{*}{ Toplam } & $<19$ age & 173 & $12,8 \%$ & 62 & $7,6 \%$ & $>0.05$ & $<0,001$ \\
\hline & $19-64$ age & 1150 & $84,8 \%$ & 730 & $88,9 \%$ & $>0.05$ & \\
\hline & $>64$ age & 33 & $2,4 \%$ & 29 & $3,5 \%$ & $>0.05$ & \\
\hline
\end{tabular}

KGY: Kapalı glob yaralanması, AGY: Açık glob yaralanması, AY: Adneksal yaralanma 


\section{B. Akova ve S.A. Kıvanç}

Tablo V. 2019 ve 2020 yıllarında Mart, Nisan, Mayıs aylarında yabancı cisim şikayeti ile başvuran hastaların karşılaş̧ırılması.

\begin{tabular}{|lccccc|}
\hline \multicolumn{1}{c}{2019} & \multicolumn{2}{c|}{2020} \\
\hline \multicolumn{1}{|c}{ Yc yeri* } & Sayı & Oran(\%) & Sayı & Oran(\%) & $\begin{array}{c}\text { Z test } \\
\text { p değeri }\end{array}$ \\
\hline Yc bulunamadı & 119 & 13,9 & 113 & 19,3 & $<0.05$ \\
Kornea & 691 & 81,3 & 441 & 75,5 & $<0.05$ \\
Tarsal konjunktiva & 31 & 3,7 & 20 & 3,4 & $>0.05$ \\
Bulbar konjunktiva & 4 & 0,5 & 6 & 1,0 & $>0.05$ \\
Çoklu & 1 & 0,1 & 3 & 0,5 & $>0.05$ \\
Ön kamera & 2 & 0,2 & - & - & - \\
Vitreus & 3 & 0,3 & 1 & 0.3 & $>0.05$ \\
Toplam* & 851 & 100,0 & 584 & 100,0 & \\
\hline
\end{tabular}

Yc: Yabancı cisim, *Tüm yabancı cisim şikayeti ile başvuran hastalardaki dağılımı göstermektedir.

Tablo VI. Periorbital yaralanmaların 2019 ve 2020 Mart, Nisan, Mayıs aylarındaki dağılımla$\mathrm{r} 1$

\begin{tabular}{|c|c|c|c|c|c|}
\hline & \multicolumn{4}{|c|}{ Adnexal Injuries } \\
\hline & & \multicolumn{2}{|c|}{2019} & \multicolumn{2}{|c|}{2020} \\
\hline & & Sayı & Oran \% & Sayı & Oran \% \\
\hline \multirow{9}{*}{$\begin{array}{l}\text { Orbita } \\
\text { yaralanma } \\
\text { tipleri }\end{array}$} & Medial duvar kırığı & 15 & 33 & 5 & 14 \\
\hline & 2 duvar kırığı & 10 & 22 & 10 & 28 \\
\hline & Alt duvar kırığı & 8 & 17 & 7 & 20 \\
\hline & Üst duvar kırığı & 6 & 13 & 6 & 17 \\
\hline & Lateral duvar kırığı & 4 & 9 & 2 & 6 \\
\hline & Maksillofasiyal yaralanma & 0 & 0 & 3 & 9 \\
\hline & Intraorbital yabancı cisim & 2 & 4 & 2 & 6 \\
\hline & Orbital hemoraji & 1 & 2 & 0 & 0 \\
\hline & Toplam orbita yaralanmaları* & 46 & 100 & 35 & 100 \\
\hline \multirow{6}{*}{$\begin{array}{l}\text { Göz } \\
\text { kapağı } \\
\text { yaralanma } \\
\text { tipleri }\end{array}$} & Göz kapağı kesisi & 40 & 36 & 17 & 26 \\
\hline & $\begin{array}{l}\text { Göz kapağı ödemi/ ekimoz/ } \\
\text { abrazyon }\end{array}$ & 63 & 57 & 43 & 66 \\
\hline & Kanalikül kesisi & 3 & 3 & 4 & 6 \\
\hline & Kaş kesisi & 2 & 2 & 1 & 2 \\
\hline & Kaş ve kirpik yanması & 2 & 2 & 0 & 0 \\
\hline & $\begin{array}{l}\text { Toplam göz kapağı yaralanma- } \\
\text { SI* }\end{array}$ & 110 & 100 & 65 & 100 \\
\hline
\end{tabular}

*Glob yaralanmalarına eşlik eden adneks yaralanmaları dahil edilmiștir
Tablo VII. Oküler travma gruplarında günlük ortalama başvuran hasta sayısının karşıllaştırılmas1

\begin{tabular}{|c|c|c|c|c|c|}
\hline $\begin{array}{l}\text { Yaralan } \\
\text { ma tipi }\end{array}$ & Yll & $\begin{array}{c}\text { Günlük } \\
\text { Hasta Sayısı }\end{array}$ & Karantina grupları & $\begin{array}{c}\text { Günlük } \\
\text { hasta sayıs }\end{array}$ & Tukey test \\
\hline & & $\begin{array}{l}\text { Ortala- } \\
\text { ma } \pm \text { SD }\end{array}$ & & Mean $\pm S D$ & $P$ değeri \\
\hline \multirow[t]{6}{*}{ KGY } & 2019 & $11.6 \pm 4.5$ & $\mathrm{HI}$ & $11.5 \pm 4.2$ & \\
\hline & & & HS & $11.9 \pm 5.3$ & \\
\hline & 2020 & $7.4 \pm 3.6$ & 1/2 karantina $\mathrm{HI}$ a & $7.4 \pm 3.4$ & $a-b \quad 0.997$ \\
\hline & & & 1/2 karantina $H S^{b}$ & $7.0 \pm 3.5$ & b-c 0.991 \\
\hline & & & Tam Karantina $^{c}$ & $7.7 \pm 4.2$ & a-c $\quad 0.999$ \\
\hline & $P$ değeri & $<0.001^{*}$ & & $<0.001^{* *}$ & \\
\hline \multirow[t]{6}{*}{$A G Y$} & 2019 & $0.3 \pm 0.6$ & $\mathrm{HI}$ & $0.4 \pm 0.6$ & \\
\hline & & & HS & $0.2 \pm 0.5$ & \\
\hline & 2020 & $0.2 \pm 0.5$ & 1/2 karantina $\mathrm{HI}$ a & $0.3 \pm 0.6$ & $a-b \quad 0.480$ \\
\hline & & & 1/2 karantina HS & 0 & b-c 0.999 \\
\hline & & & Tam Karantinac $^{c}$ & $0.05 \pm 0.22$ & a-c $\quad 0.424$ \\
\hline & $P$ değeri & $0.201^{*}$ & & $0.083^{* \star}$ & \\
\hline \multirow[t]{6}{*}{ AY } & 2019 & $1.0 \pm 1.1$ & $\mathrm{HI}$ & $0.9 \pm 1.1$ & \\
\hline & & & $\mathrm{HS}$ & $1.4 \pm 1.1$ & \\
\hline & 2020 & $0.7 \pm 0.9$ & 1/2 karantina $\mathrm{HI}$ a & $0.6 \pm 0.9$ & $a-b \quad 0.528$ \\
\hline & & & 1/2 karantina $\mathrm{HS}^{b}$ & $1.1 \pm 1.0$ & b-c 0.898 \\
\hline & & & Tam Karantina $^{c}$ & $0.8 \pm 1.0$ & a-c $\quad 0.962$ \\
\hline & $P$ değeri & $0.015^{*}$ & & $0.015^{* *}$ & \\
\hline \multirow[t]{6}{*}{ Yanıklar } & 2019 & $1.5 \pm 1.4$ & $\mathrm{HI}$ & $1.6 \pm 1.5$ & \\
\hline & & & HS & $1.4 \pm 1.2$ & \\
\hline & 2020 & $0.6 \pm 0.8$ & 1/2 karantina $\mathrm{HI}$ a & $0.6 \pm 0.8$ & $a-b \quad 0.997$ \\
\hline & & & 1/2 karantina HS & $0.7 \pm 1.0$ & b-c 0.986 \\
\hline & & & Tam Karantinac & $0.5 \pm 0.8$ & a-c 0.998 \\
\hline & $P$ değeri* & $<0.001^{*}$ & & $<0.001^{* *}$ & \\
\hline
\end{tabular}

*t test, **One-Way ANOVA test, KGY: Kapalı glob yaralanması, AGY: Açık glob yaralanması, AY: Adneksiyal yaralanma, Hİ:Haftaiçi, HS:Haftasonu, 1/2 karantina Hİ: Haftaiçi yarı karantina, $1 / 2$ karantina HS: Haftasonu yarı karantina, SD: Standart deviasyon.

\section{Tartışma ve Sonuç}

Hastanemiz, Marmara Bölgesi'nin referans üçüncü basamak merkezlerinden biridir. Pandemi döneminde de birçok göz travma başvurusu olmuştur. Acil servise başvuran göz travması sayısında bir önceki yıla göre azalma olduğunu tespit ettik. Bununla birlikte, travma mekanizmalarının ve türlerinin dağılımında da değişiklikler gördük. Ev, okul ve nedeni bilinmeyen göz yaralanmaları oranı önemli ölçüde azaldı. Herhangi bir şekilde sıçrayan bir yabancı cisim ile yaralanma oranının önemli ölçüde arttığını bulduk. Ancak kapalı glob yaralanma oranlarının arttığ ve yanık oranlarının azaldığ 1 , açık glob yaralanma insidansının değişmediği görüldü. Wu ve arkadaşları 23 Mart-20 Nisan 2020 tarihleri arasındaki "evde kalma" döneminde göz acil durumları için başvuran hasta sayısında önemli bir azalma olduğunu bildirmişlerdir. Ayrıca göz travmalar1 insidansının stabil olduğunu, gözlemlemişlerdir. 


\section{COVID 19 Pandemisi Döneminde Oküler Travmalar}

Gözlerde ciddi oküler travma 2019'da 1372 hastanın 87'sinde $(\% 6,3)$ ve 2020'de 1058 hastanın 62'sinde $(\% 5,9)$ görülmüştür. Ağır oküler travma Wu ve arkadaşları tarafindan göz kapağı laserasyonları, oküler laserasyonlar, glob rüptürü, kimyasal yanıklar, hifema, göz içi yabancı cisim, orbital yabancı cisim, travmatik vitreus hemoraji, sklopetarya, kommosyo retina, travmatik retinal yırtık ve dekolmanları ve koroidal hemoraji, olarak tariflenmiştir ${ }^{10}$. Pellegrini ve arkadaşları 2019 'da 10 Mart ile 10 Nisan arasında 354 göz yaralanması bildirilirken, 2020'de aynı dönemde 112 göz yaralanması tespit etmişlerdir. Çalışmalarında pandemi döneminde göz yaralanmalarında \%68,4 oranında çarpıcı bir azalma göstermişlerdir ve pandemi dönemindeki davranışsal değişiklikleri karantina sırasında daha düşük travma riski ile ilişkilendirmişlerdir ${ }^{11}$.

Shah ve arkadaşları 2019 ve 2020 yılı 22 Mart-30 Nisan tarihleri arasındaki başvuruları birbiri ile karş1laştırmışlardır. 2019 yılında oftalmolojik acil servise başvuran 157 hasta incelendiğinde \%48,4'ü oküler travma ile başvuran ve göz travmalarının \%9'unun (7 hasta) çocuk olduğu görüldü. 2020 pandemi döneminde 148 oftalmolojik acil başvurunun \%52,7'sinin göz travması nedenli olduğu ve bunların \%30'unun (24 hasta) pediatrik yaş grubunda olduğu tespit edilmiş$\operatorname{tir}^{12}$. Karantina döneminde pediatrik yaş grubunda göz travması insidansının arttığını gözlemlemişlerdir ${ }^{12}$. Wu ve ark. 2020 döneminde okulda oküler travma olmadığını tespit etmişlerdir ${ }^{10}$. Bizim de bulgularımız benzerdir; okul kazalarının görülme sıklığı istatistiksel olarak önemli ölçüde azalmış bulundu. Bunun sebebi ise 2020 yılında 19 yaş altının sürekli karantina altında olması ve çevrimiçi eğitim yapıyor olmasıydı. Pellegrini ve arkadaşları karantina sırasında göz yaralanması olan çocuk ve ergen oranının $\% 15$ 'ten $\% 8$ 'e düştügüün̈ bildirmişlerdir ${ }^{11}$. Okul kapalıyken çocuklarda okul ve spor yaralanmalarındaki azalmanın pandemideki davranışsal değişikliklerden kaynaklandığını belirtmişler$\operatorname{dir}^{11}$. Çalışmamızda, Pellegrini ve arkadaşlarının bulgularına benzer şekilde, göz yaralanmalarında önemli bir azalma bulduk. Karantinaya alınan 19 yaş altı bireylerin göz acil başvuru oranlarının hafta içi \%17'den \%11'e, hafta sonları ise \%16'dan \%10'a düştüğü görüldü. 2020 yılında çocuk yaş gruplarında çalışma döneminde tam karantina olduğu için sokakta, okulda ve spor faaliyetlerinde göz yaralanmalarının azaldığını düşünmekteyiz. Wu ve arkadaşları, evdeki yaralanmaların önemli ölçüde arttığını tespit etmişler$\operatorname{dir}^{10}$. Bunun, evde kalan insanların amatör ev geliştirme projeleriyle ilgilenmelerinden kaynaklandığını düşünmektedirler ${ }^{10}$. Pellegrini ve arkadaşları karantina sırasında ev içi faaliyetlere bağlı kaza ve bitkilerle yaralanma oranlarının arttığı tespit etmişlerdir ${ }^{11}$. Çalışmamızda evde yaralanma vakalarının azaldığı görüldü. Diğer çalışmalardan farklı olan bu sonucun özellikle evdeki çocukların karantina dönemlerinde ailelerinin gözetimi altında olmalarından ve karantina dönemlerinde davranış açısından daha dikkatli olmalarından kaynaklandığını düşünüyoruz. Bizim çalışma- mızda da bitki ile yaralanmaların insidansı artmıştır; Bitki zedelenmesi sıklığının bir önceki yıla göre daha fazla olmasının sebebinin, karantina dönemlerinde bahçelerinde tarlalarında çalışan kişilerden kaynaklandığını düşünüyoruz. Poyser ve arkadaşları Birleşik Krallık'ta oküler travma sayısında \%43,6 azalma olduğunu bildirmişlerdir. Yabancı cisim ve kimyasal yaralanma oranlarını 2019 ve 2020 'de benzer bulmuşlardır. 2019-2020 yılları arasında orbita kırı̆̆ı sayısında \%46 azalma olduğunu bildirmişlerdir ${ }^{13}$. Çalışmamizda ise firlayan yabancı cisim ile yaralanma insidans1 2019'dan 2020'ye artmıştı. Diğer yaralanma nedenlerindeki göreceli azalışın bu sonucu doğurduğu kanaatindeyiz. Kimyasal yanık insidansı azalmıştı. Mart-Mayıs 2020 döneminde bazı sanayi kollarında üretimlerin durması sonucu kimyasal yaralanmaların azaldığını düşünüyoruz; Marmara bölgesi, daha önce de belirtildiği gibi, Türkiye'nin en çok sanayileşmiş bölgesidir. Ayrıca çalışmamızda adneksiyal yaralanma türünün dağılımı, 2020'de Mart, Nisan ve Mayıs aylarında 2019'dan önemli ölçüde farklı bulundu.

Çalışmamızda 2019 hafta içi ve hafta sonu olarak 2 gruba, 2020 hafta içi yarı karantina, hafta sonu karantina ve tam karantina olmak üzere 3 gruba ayrıldı. Her bir yaralanma türü için günlük ortalama başvuru sayısı, 2019 ve 2020 arasında KGY, AY ve yanıklarda önemli ölçüde farklıydı. Açık glob yaralanmaları için her iki yılda da benzer bulundu. Türkiye'de üretime devam etmek için haftanın farklı günlerinde farklı karantina biçimleri uygulandı. Sonuçlar KGY grubunda $7.7 \pm$ 4.2 hasta / gün, AGY grubunda $0.05 \pm 0.22$ hasta / gün, AY grubunda $0.8 \pm 1.0$ hasta / gün ve Yanık grubunda $0.5 \pm 0.8$ hasta / gün olduğunu gösterdi. Bilgimize göre çalışmamız, literatürde büyük sayısal veriler içeren ve karantinanın farklı dönemlerini göstermesi bakımından ilk çalışmadır. Bu verileri elde etmenin önemli yönlerinden biri de büyük sağlık merkezlerinin pandemi, deprem, sel gibi afetlerde karşılaşacakları olası hasta durumları hakkında fikir sahibi olmaları ve duruma hazırlıklı olmalarıdır. Aynı zamanda bu veriler afet durumlarında sağlık kurumunda hizmet verecek sağlık personeli ve kaynakların paylaşımında da önemlidir.

\section{Etik Kurul Onay Bilgisi:}

Onaylayan Kurul: Uludağ Üniversitesi Tıp Fakültesi Klinik

Araştırmalar Etik Kurulu.

Onay Tarihi: 24.02 .2021

Karar No: 2021-4/33

Araștırmacı Katkı Beyanı:

Fikir ve Tasarım: S.A.K., B.A.; Veri toplama ve işleme: S.A.K., B.A.; Analiz ve verilerin yorumlanması: S.A.K., B.A.; Makalenin önemli bölümlerinin yazılması S.A.K., B.A.

Destek ve Teşekkür Beyanı:

Verilere ulaşmadaki desteğinden dolayı Dr. Sevde İşleker'e teşekkür ederiz.

Çıkar Catıșması Beyanı:

Makale yazarlarının çıkar çatışması beyanı yoktur. 


\section{B. Akova ve S.A. Kıvanç}

\section{Kaynaklar}

1. World Health Organization. https://www.euro.who.int/en/ health-topics/health-emergencies/coronavirus-covid-19/novelcoronavirus-2019-ncov (Access December 20,2020)

2. Birkmeyer JD, Barnato A, Birkmeyer N, Bessler R, Skinner J. The Impact of the COVID-19 pandemic on hospital admissions in the United States. Health Affairs 2020 39:11, 2010-2017

3. Nourazari S, Davis SR, Granovsky R, Austin R,Straff DJ, Joseph JW, Sanchez LD. Decreased hospital admissions through emergency departments during the COVID-19 pandemic, American Journal of Emergency Medicine,https://doi.org/ 10.1016/j.ajem.2020.11.029

4. Turkish Health Ministry, https://covid19.saglik.gov.tr/ (Access December 20, 2020)

5. Turkish Health Ministry, https://covid19.saglik.gov.tr/TR68443/covid-19-durum-raporu.html (Access December 20, 2020)

6. Kıvanç SA, Akova Budak B, Skrijelj E, Tok Çevik M. Demographic Characteristics and Clinical Outcome of Work-related Open Globe Injuries in the Most Industrialised Region of Turkey. Turk J Ophthalmol. 2017 ;47(1):18-23.

7. Kıvanç SA, Akova-Budak B, Olcaysü OO, Çevik SG. Sociodemographic status of severely disabled and visually impaired elderly people in Turkey. Arq Bras Oftalmol. 2016 ;79(1):24-9.
8. Yildiz M, Kıvanç SA, Akova-Budak B, Ozmen AT, Çevik SG. An Important Cause of Blindness in Children: Open Globe Injuries. J Ophthalmol. 2016;2016:7173515.

9. Olcaysü OO, Kıvanç SA, Altun A, Çinici E, Altınkaynak H, Ceylan E. Causes of Disability, Low Vision and Blindness in Old Age. Turkish Journal of Geriatrics. 2014; 17(1):44-49.

10. Wu C, Patel SN, Jenkins TL, Obeid A, Ho AC, Yonekawa Y. Ocular trauma during COVID-19 stay-at-homeorders: a comparative cohor tstudy. Curr Opin Ophthalmol. 2020 Sep;31(5):423-426.

11. Pellegrini M, Roda M, Di Geronimo N, Lupardi E, Giannaccare $\mathrm{G}$, Schiavi C. Changingtrends of oculartrauma in the time of COVID-19 pandemic. Eye (Lond). 2020 Jul;34(7):1248-1250

12. Shah, Mehul\&Netralaya, Drashti\&Bhasin, Purendra\&Jyot, Rayan\&Dr, Netralaya\&Shah, Shreya\&Patel, Heena. (2020). Impact of COVID-19 Lockdownperiod on OcularTrauma. 10.21203/rs.3.rs-49393/v1.

13. Poyser A, Deol SS, Osman L, Kuht HJ, Sivagnanasithiyar T, Manrique R, Okafor LO, DeSilva I, Sharpe D, Savant V, Sarodia U, Sarvananthan N, Chaudhuri R, Banerjee S, Burns J, Thomas MG. Impact of COVID-19 pandemic and lockdown on eye emergencies. Eur J Ophthalmol. 2020 19:1120672120974944. 